\title{
Beach slope distribution mapping using UAV in the Cirebon coastal area
}

\author{
Umar Abdurrahman ${ }^{1 *}$, Indrawan Fadhil Pratyaksa ${ }^{1}$, Totok Suprijo ${ }^{2}$ and Hansan Park ${ }^{1,3}$ \\ ${ }^{1}$ Korea-Indonesia, Marine Technology Cooperation Research Center, Cirebon 45611, Indonesia \\ ${ }^{2}$ Faculty of Earth Sciences and Technology, Bandung Institute of Technology, Bandung 40116, Indonesia \\ ${ }^{3}$ Korea Institute of Ocean Science and Technology, Busan 49111, Korea
}

\begin{abstract}
The beach slope is usually estimated using the conventional ground survey, causing the availability of this parameter data to be limited in some areas. Meanwhile, this parameter is considered crucial in the study of shoreline changes and coastal area protection as well as other coastal morphodynamic research. The aim of this study is to demonstrate an efficient technique to calculate the beach slope as well as its distribution in an area. In the daily intertidal period, the beach profile is assumed to be a static planar beach state which does not change due to the insignificant effect of erosion and accretion process. First, the shoreline data set was delineated from the tidal-varied orthomosaic using the UAV. The beach slope is then calculated by comparing the difference in tide level with the difference in the horizontal distance of shoreline points along a cross-shore transect at different times. The utilization of UAV allows mapping the shoreline in an area in several different tidal conditions, allowing the distribution of the beach slope also be mapped. This technique was then applied in the Cirebon Coastal Area and found an average beach slope of 0.105 with 0.100 being the slope class with the highest number of distributions. It was also found that due to the presence of mangroves and coastal structures, no slope conditions dominated this area. The result of beach slope calculation using this technique shows suitability with other studies and reveals UAVs' potential in mapping the beach slope distribution more efficiently.
\end{abstract}

\section{Introduction}

The beach profile, as part of beach morphology, is a crossshore intersection at high tide and extends from a backshore cliff or dune to the inner continental shelf or up to a position where sediment transport due to waves and currents is not active [1]. This feature is one of the most studied features in the study of coastal form and structure systems. The beach profile parameter will affect the beach as an area for the recreation industry [2,3], habitats for certain biota [4,5], and also spatial planning and coastal area hazard assessment $[6,7]$.

While the beach slope refers to the slope of the foreshore or beach face of the beach profile as a comparison of the difference in elevation and the difference in distance over the range of the area [8]. Tidal variability and wave swash in a regular state will continuously wash the beach face as part of the beach profile [9]. In another definition, the beach slope is also can be defined as the steepest part along the cross-shore bed profile. The difference in elevation is calculated from the difference in the usual or average shoreline elevation and the elevation of the depth of closure, a location where there is no significant change in bottom elevation or point of the offshore limit water depth of sediment transport. Meanwhile, the difference in distance is calculated from the difference in the horizontal distance of the two parameters. From the difference in elevation and the difference in distance, the beach slope is then calculated as a cross-shore gradient of the beach face $[10,11]$. Because it is measured under the usual conditions or average shoreline, the beach slope has spatial and temporal variability depending on various coastal physical parameters.

Temporal variability of beach slope can be dependent on tidal cycles, seasonal waves, long-term erosionaccretion, extreme storm events, and anthropogenic influences such as beach nourishment and scraping $[1,12]$.

Beach slope is an important parameter that can affect the hydrodynamics and morphology of the surf zone. This parameter regulates wave transformation and total surface elevation, and can also be associated with geomorphological processes in various temporal scales [13], so that when these parameters are measured or estimated they can provide information on potential erosion and accretion hazards as well as other uses $[11,14]$.

For example, the use of beach slope parameters is also needed in shoreline change studies for shoreline correction due to the tidal effect. [15] at the postprocessing stage, the position of the extracted shoreline from the Sentinel satellite was corrected based on tidal elevation and beach slope data in his research to study shoreline changes in Canggu Coastal Area, Indonesia. In

\footnotetext{
* Corresponding author: umarabd@mtcrc.center
} 
[16] tidal correction was applied to the extracted shoreline from Landsat based on beach slope and tidal elevation in Gold Coast, Australia. [17] conducted a specific study on the effect of tidal correction on shoreline mapping in Jepara, Indonesia based on beach slope and tidal prediction data. [18] corrected the position of the shoreline due to tides based on the value of beach slope and tidal water level at Nanakita River mouth, Japan. [19] and [20] calculates the cross-shore horizontal shift or as tidal correction by dividing the difference in distance between the reference tidal datum and the measured or modeled tidal elevations which coincide with the time of images by the beach slope specific to the study site. Tidal correction is applied in shoreline variability studies based on satellite imagery and implemented in web-based applications that can cover the worldwide.

In fact, involving tidal correction in shoreline change studies is absolutely necessary, especially in the higher spatial resolution of shoreline data compared to shoreline changes due to tidal effect [18,21]. The use of the assumption of beach slope uniform globally which is often used, i.e., with a value of 1:100 can result in an erroneous analysis. For example, the assessment of the retreat of the shoreline due to Sea Level Rise, on average, would underestimate $40 \%$ when using this assumption [10]. Likewise, in its use in shoreline correction due to daily tides, this assumption has the potential to cause errors in the results obtained.

In several studies, the grain size of the bottom sediment and wave conditions have been tried to estimate the beach slope. This is possible because beach slope can change if there is a change in the size of the sediment, as well as if the wave conditions change. In general, the beach slope will be steeper if the sediment grain size is larger (pebbles, cobbles, or boulders) and will be gentler if the sediment grain size is smaller (clay, silt, or sand) $[8,22]$.

[23] investigated the relationship between bed sediment grain size and beach slope. First of all, the beach exposure is determined based on significant offshore wave heights that exceed 12 hours per year. The beach exposure criteria are then used to determine the choice of the equation used. The equation is compiled based on data on grain size, beach slope, and beach exposure from 181 sand beaches spread all over the world. Calculation of the beach slope using this equation shows 95\% good prediction results with an error of less than 50\%. Although we have succeeded in estimating the beach slope based on bed sediment grain size, some amount of scattering is still expected. This is because there are also seasonal differences in beach slope due to the influence of erosion and accretion processes that cannot be described by this equation.

Several other studies that attempted this were also considered not to provide a clear enough relationship between sediment grain size and beach slope [24-26]. The use of assumptions such as uniform bed sediment grain size and lack of consideration of wave variability conditions were considered too tight and not reliable enough so that they indicated disagreement with the data of several measurements [11].

Besides being estimated by bed sediment grain size and wave conditions, beach slope can be measured directly by field survey. GPS survey is one common method of obtaining coastal topographic data, including beach slope. For example, in [27] GPS was mounted to an All-Terrain Vehicle (ATV). This method gets a position value of over 10,000 irregularly spaced points. By performing a series of interpolations, a regularly spaced digital terrain model can then be obtained. Since topographic data is obtained covering an area, more crossshore profile lines will be obtained, allowing for the spatial distribution of beach slopes. However, this method is limited by the accessibility that both ATVs and humans can pass through. For example, in areas where the beach is muddy or full of coastal vegetation, measuring position and elevation will be difficult and considered ineffective. Especially in estimating the beach slope on a wide spatial scale such as global, national, and regional events, which is still a major challenge in using this method [13].

The use of Terrestrial Laser Scanner (TLS) and airborne-Light Detection and Ranging (LiDAR) scans can also be performed and it is possible to get very detailed and accurate results, but the process is very complicated because the dataset that is collected is relatively large. Both also require relatively high expenses as well as the operational costs of the survey when compared to the simple method.

There is also a simpler traditional method, i.e., the peg-lines and the [28] method. Both methods have the same concept of beach slope calculation. This method is done by first measuring the distance from a benchmark to two rods using a measuring tape in a direction perpendicular to the coast. The change in elevation between the two rods is then calculated using a horizontal view with the markers on each rod as a reference. Along the profile line, this process is repeated at each successive measurement point. Then, the actual position and elevation can be obtained from relative measurement of position and elevation based on previously known benchmark elevation. This method is classified as a lowcost technique because it only requires simple equipment and only requires two people.

However, measurement of the difference in elevation by two people like this has the potential to have errors due to limited visibility and is considered labor intensive so that it is limited to the number of beach profile transects measured [27,29]. Apart from that, this method is still considered a reliable method as observation data, so it is still used as comparison data for validation of more sophisticated techniques.

Many challenges will be faced when measuring beach profile with high temporal (hourly to decadal measurement) and spatial (3-dimensional measurement). The GPS, TLS, LiDAR, peg-lines, and Emery methods are recognized to be able to obtain data with high accuracy. However, this method has disadvantages in the form of high costs or labor-intensive. Moreover, longterm data is needed to be able to provide a representative trend $[27,30]$.

The use of UAVs, especially consumer-grade drones, has the characteristics of being a relatively low-cost tool and has a high degree of automation compared to the TLS and LiDAR methods. When compared with simple methods, the use of UAVs can still provide the same accuracy while covering a wider area [31-34]. The use of 
UAVs has been widely applied and has resulted in various achievements and improvements in other coastal dynamics studies, such as calculating beach volume change [35], determining erosion and accretion rates [5,31,32,36-38], coastal topographic surveys [39,40], and many other applications.

This study will demonstrate an efficient technique to calculate the beach slope as well as its distribution in an area. The concept in calculating the beach slope with this method is to compare the tidal elevation and the horizontal distance of the cross-shore shoreline at two different times. The beach profile is assumed to be a static planar beach state which does not change due to the insignificant effect of erosion and accretion process. In simple terms, this method applies Emery's concept in measuring the beach profile, while the horizontal distance will be calculated based on the results of orthomosaic UAV mapping and the tidal elevation will be predicted from the tidal model.

In the following section, the research method will be explained. The study site used in this study is briefly described and details the method used. In Section 3, the results of orthomosaic and beach slope calculations will be presented, as well as further analysis of these results. Future improvement of the method as well as the obstacles that may be faced when carrying out the same technique and the comparison of the beach slope resulting from the use of the UAV and the estimated beach slope are presented in Section 4 and then followed by Section 5 which includes conclusions.

\section{Materials and methods}

Utilization of drone mapping technology in mapping the spatial distribution of the beach slope which is calculated based on the position of the shoreline and tidal elevation. This concept has already been applied to a study conducted by [30]. Beach slope is obtained by dividing rise (vertical difference between two tidal elevations) by run (horizontal difference between two shorelines) which is timed and applied in Kristianstad eastern coast, Sweden to conduct a temporal and spatial quantitative analysis of coastal erosion. In [21] the same concept has also been applied. Beach slope is calculated based on the comparison of two waterlines (shoreline, which has been extracted from satellite image) and water line heights (tidal elevation, obtained from tidal harmonic analysis) which are timed to match. This beach slope value is then used to correct extracted shoreline from a satellite image to study shoreline change in Yellow River Delta, China. [41] have also used the same concept in calculating beach slope. The tidal elevation was obtained from the computational model and the distance offshore from the shoreline was measured from a reference, both of which were compared at two different times. This comparison is then determined as the beach slope and used to obtain the MSL-datum-based shoreline position. This method is applied to estimate shoreline change considering the tidal effect in Waisanding sandbar, Taiwan.

\subsection{Study sites}

To show the efficiency of UAV utilization, Cirebon coastal area (CCA) was used as a study site in this research. This area is located on the north coast of Java Island which covers Cirebon District and Cirebon City. Based on [42] the population in CCA reaches 2,513,955 people and makes this area the third most populous coastal area among cities and regencies in West Java. This area exhibits rapid urban development with people's activities dominated by fisheries, agriculture, and industry. This activity has the potential to cause various problems in the coastal area, for instance, salt intrusion, domestic and industrial water pollution, as well as erosion and accretion.

CCA has a shoreline of $70 \mathrm{~km}$ with a beach type dominated by mud and some parts filled with mangrove vegetation. CCA experiences coastal dynamics that are dominated by accretion, although several studies have also shown significant erosion in certain areas $[43,44]$. Wave variability in CCA waters is dominated by seasonal variability with a significant wave height range of $0.5-1$ meter. Ocean currents in the west monsoon can reach 1 $\mathrm{m} / \mathrm{s}$ and in the east monsoon, it reaches $0.7 \mathrm{~m} / \mathrm{s}[45,46]$.

Two beach sites along the entire CCA were selected and mapped at the end of September 2020. Both belong to the sand-mud beach type with mangrove vegetation in some parts of the area. The first site is Karanganom Village, Cirebon City which represents urban and residential areas. The second site is Rawaurip Village, Cirebon Regency, which represents a salt pond area and an area with less human influence. At each site, sediment samples were also taken as additional data in analyzing the beach slope. The samples obtained were then sent to the laboratory to obtain the sediment size distribution.

\subsection{Flight mission settings}

In this study, DJI Phantom 4 Pro V2.0 (1-inch CMOS sensor with $20 \mathrm{M}$ effective pixels) was used to collect aerial photos of the study sites. Automated flight missions were conducted within the Pix4D Capture application with $80 \%$ overlap. The angle of the camera was set to 90 degrees to collect the look-down photograph. Flying altitude is set at 80 meters and gets an expected resolution or ground sample distance (GSD) of about $2 \mathrm{~cm} /$ pixel. Meanwhile, the area and shape of the flight mission are set differently to be able to follow the shoreline stretch conditions at each location (Fig. 1).

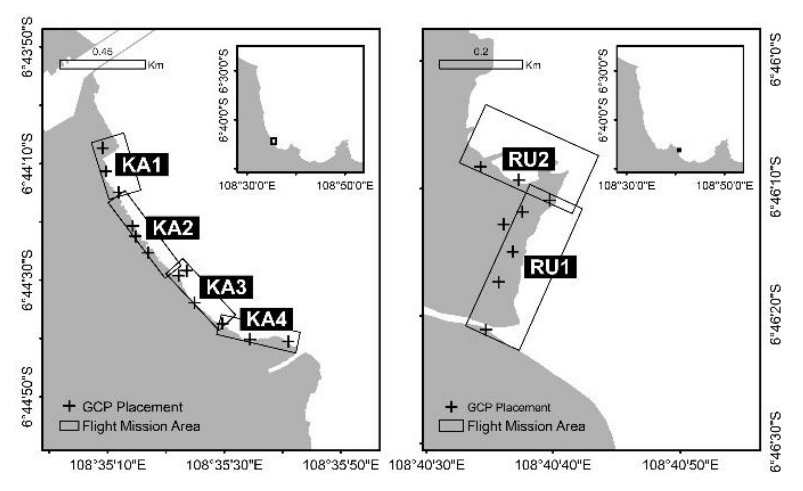

Fig. 1. Flight area (square) and GCPs placement (plus) 
In order to maintain the accuracy, 3-5 temporary Ground Control Points (GCPs) (size $1 \mathrm{~m} \times 1 \mathrm{~m}$ ) are proportionally placed in each survey area. The positions of the GCPs were then measured using the GNSS Leica GS18 T and were used to calibrate the position of aerial photos in the post-processing stage. The aerial photo collected during the flight missions were processed using Pix4D Mapper following the stages of alignment, alignment optimization, and the resulting orthomosaic process. Detailed setting of UAV flight mission is provided in Table 1.

Table 1. Flight mission setting details

\begin{tabular}{lccccc}
\hline Location & Code & $\begin{array}{c}\text { Area } \\
(\mathrm{m} \mathrm{sq} .)\end{array}$ & $\begin{array}{c}\text { Duration } \\
(\mathrm{min}: \mathrm{sec})\end{array}$ & $\begin{array}{c}\text { Error for } \\
\text { orthomosaic } \\
(\mathrm{m})\end{array}$ & $\begin{array}{c}\mathrm{GSD} \\
(\mathrm{cm} / \mathrm{px})\end{array}$ \\
\hline Karanganom, & KA1 & $175 \times 310$ & $08: 30$ & $0.024 \mathrm{~m}$ & 2.23 \\
Cirebon & KA2 & $110 \times 500$ & $09: 00$ & $0.024 \mathrm{~m}$ & 2.22 \\
City & KA3 & $120 \times 405$ & $09: 00$ & $0.480 \mathrm{~m}$ & 2.21 \\
& KA4 & $110 \times 425$ & $08: 30$ & $0.440 \mathrm{~m}$ & 2.24 \\
\hline Rawaurip, & RU1 & $140 \times 370$ & $08: 30$ & $0.023 \mathrm{~m}$ & 2.26 \\
Cirebon & RU2 & $155 \times 300$ & $08: 30$ & $0.046 \mathrm{~m}$ & 2.26 \\
District & & & & & \\
\hline
\end{tabular}

This flight mission setup costs about 10 minutes, making it possible to complete two flight missions with 1 normal capacity battery. Each flight mission area is mapped at least twice with an interval of 2 hours. This repeated mapping aims to obtain the variation of the shoreline with respect to time as well as to tidal conditions. The 2-hourly mapping carried out in one day can fulfill the assumption of the beach profile as a static planar beach where the variation of the water line is entirely caused by the rise and fall of the tide. This assumption makes it possible to estimate the beach slope with a linear fit. Meanwhile, on a long-term time scale, the beach continues to experience erosion and accretion, causing the simple linear fit to be significantly underestimated [13].

\subsection{Shoreline data extraction}

After the orthomosaic has been obtained, the next step is to identify and extract shoreline data. This stage is carried out by visual interpretation on the GIS processing application, ArcGIS 10.5. The use of visual interpretation is actually often said to have inherent problems because the determination is subjective [47], especially in lowresolution images. However, the use of UAVs and flight mission settings in this study is considered to have good enough resolution to easily identify shorelines.

The shoreline ideally coincides with the physical interface between the sea and land or the wet/dry line [48]. Meanwhile, in this study shoreline is identified with a proxy in the form of High-Water Level (HWL) which is the boundary between the water surface (specific at high tide) and the land. This proxy is the most commonly used because it is not only the most effective in line with the wet/dry line [49] but also the easiest to identify, which is the boundary between dark and light beaches due to wave run-up. However, this proxy is limited in its use due to the condition of the study sites containing mangrove vegetation. In areas where there is mangrove vegetation, the vegetation line in the form of a seaward edge of dune vegetation proxy is chosen [50].

\subsection{Tidal prediction}

After the time-varying shoreline data set was obtained, the tidal elevation corresponding to the time of image acquisition was determined from the Tidal Model Driver (TMD) [51] with the TPXO 7.2 model [52]. The set of beach positions has been obtained from the survey, covering 4 tidal conditions in Lemahwungkuk (28-29 September 2020) and 2 tidal conditions in Pangenan (30 September 2020), indicated by the black circle in the tidal time-series graph (Fig. 2). A value of zero on the tidal elevation time series chart shows MSL in one full tidal cycle (around 19 years). The tidal elevation in CCA has a daily tidal run-up of about $0.5 \mathrm{~m}$ and shows mixed semidiurnal type. The daily highest water occurs at around 6 am and the daily lowest water occurs at around $3 \mathrm{pm}$.

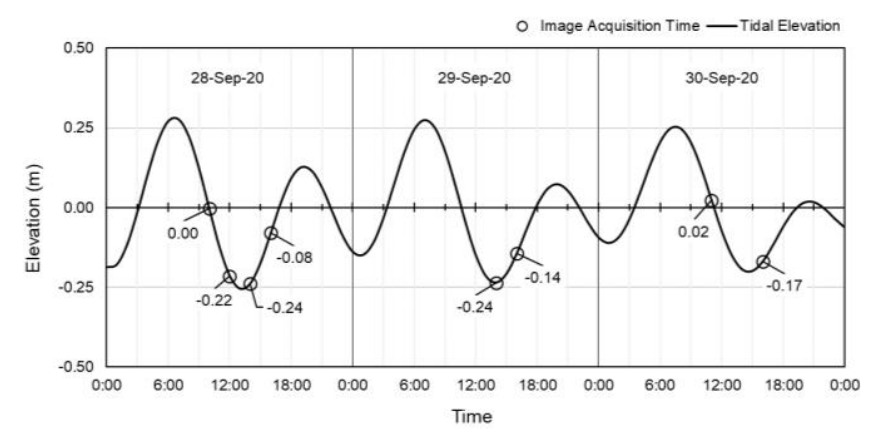

Fig. 2. Tidal elevation

\subsection{Beach slope calculation}

Ideally, beach slope is measured in the area starting from the highest point reached by high tide and the lowest point reached by low tide. This definition is most often used in coastal science [22]. However, this definition can be limited to tides, as parameters that are easy to predict, while phenomena such as run-up of waves and storm events are difficult to predict. Moreover, extreme vertical measures, such as the highest and lowest astronomical tides with a period of 19 years, will be difficult to find to fully define the area that includes the beach slope. To simplify this, the beach slope in this study will be defined based on the linear regression of the elevation to the horizontal distance perpendicular to the beach obtained during the measurement. 


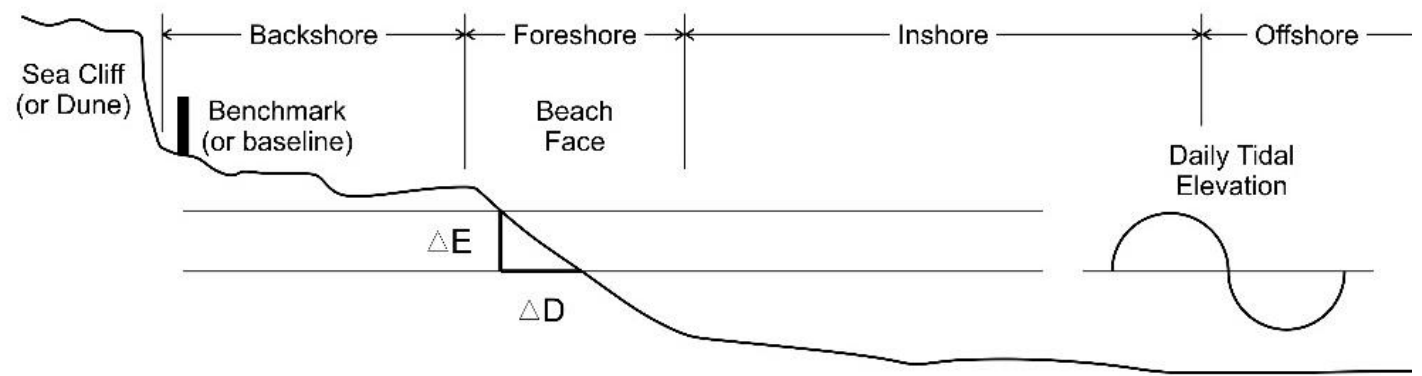

Fig. 3. Beach slope calculation illustration

The tidal elevation at each time of the image acquisition can be used directly in the calculation of the beach slope. Meanwhile, the extracted shoreline data requires additional processing. Determination of the horizontal distance of the cross-shore shoreline and ArcGIS software extension, Digital Shoreline Analysis System (DSAS), are used [53]. This software was developed by USGS and is commonly used in shoreline changes calculation $[21,49]$. In simple, a DSAS begins by creating a baseline that is relatively parallel to the entire shoreline under consideration. At the baseline, a transect is made, which is a line perpendicular to the baseline, starting from the baseline until it intersects with the furthest shoreline in the offshore direction. The distance on the transect measured from the baseline point to the intersection with the shoreline is used as the horizontal distance of the cross-shore shoreline (Fig. 3). After this value is obtained, the beach slope can simply be calculated by using Equation 1 (for 2 datasets), where $s$ is elevation, $E$ is vertical elevation in meters, and $D$ is horizontal distance in meters, or by applying linear regression (for more than 2 datasets).

$$
s=\frac{\Delta E}{\Delta D}
$$

\section{Results}

\subsection{Tidal-varied orthomosaic and shoreline}

The result of aerial photo processing is orthomosaic and further processing produces shoreline data, both of which tide and time-varied. All of the orthomosaic are then plotted onto a map for each area (Figs. 4 and 5). From the orthomosaic map, it can be seen that irregular reflections of sunlight on the surface of the water are due to the sun's high position, especially during the day $(10 \mathrm{am}-4 \mathrm{pm})$. This condition needs to be avoided to reduce misalignment on the water surface. While in this study, this problem is not too significant because the identified shoreline is on the mainland as HWL.
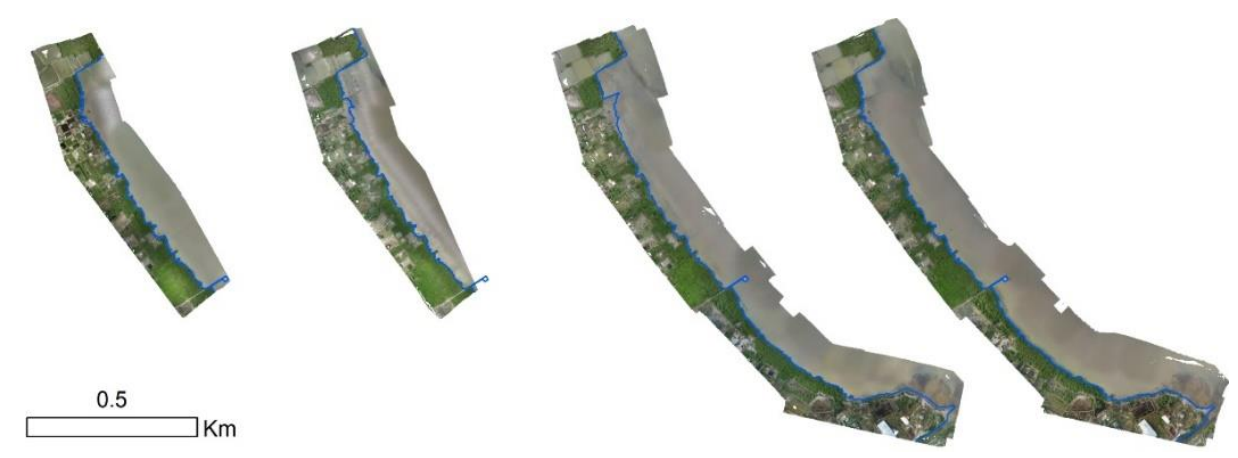

Fig. 4. Time-varied orthomosaic and its extracted shoreline for Karanganom area (10 pm, 12 pm, 2 pm, 4 pm)
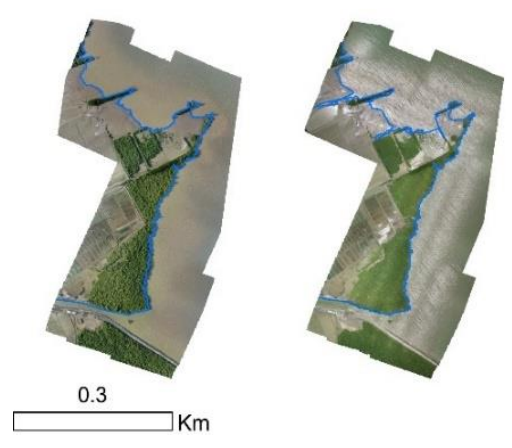

Fig. 5. Time-varied orthomosaic and its extracted shoreline for Rawaurip area (11 pm, 4 pm)
The overlay of the time-varied extracted shoreline map shows shoreline changes to tidal conditions more clearly (Fig. 6). In some parts of the area, there are significant differences in shorelines and there are also shorelines that tend to remain unchanged, especially in areas with mangrove vegetation. Areas that experienced significant changes, mostly open areas with sand or mud as the type of beach. In all areas, the beach slope will be calculated regardless of the type of beach. Areas with large changes in shoreline due to tidal effect are expected to provide gentler and steeper slopes for the opposite, while no changes in no slope beach will be expected. 


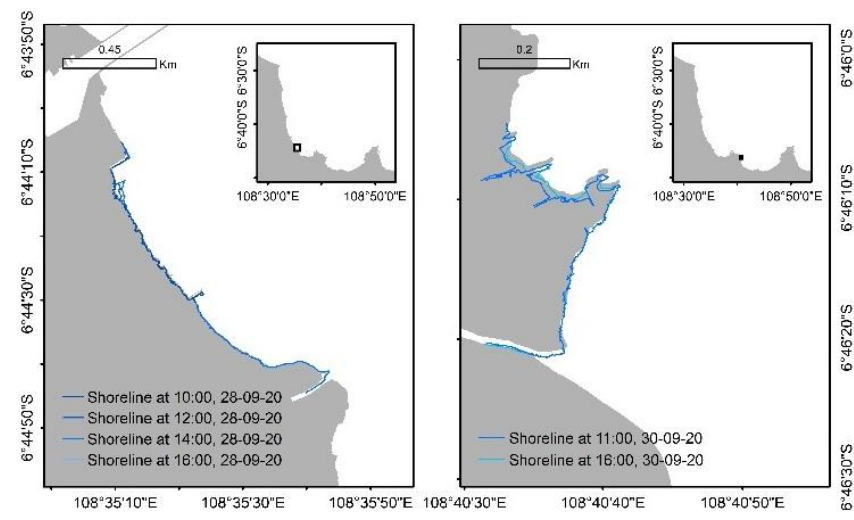

Fig. 6. Time-varied extracted shoreline for Karanganom (left) and Rawaurip (right)

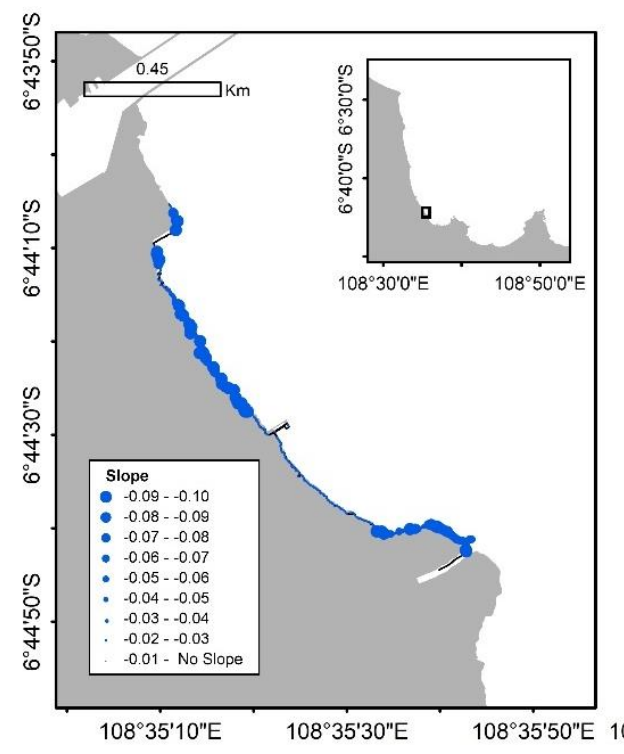

Fig. 7. Slope distribution for Karanganom (left) and Rawaurip (right)

\subsection{Beach slope frequency distribution}

In getting a broad overview of the beach slope for the study sites, the beach slope value is then visualized into a histogram to analyze its distribution quantitatively (Fig. 8).

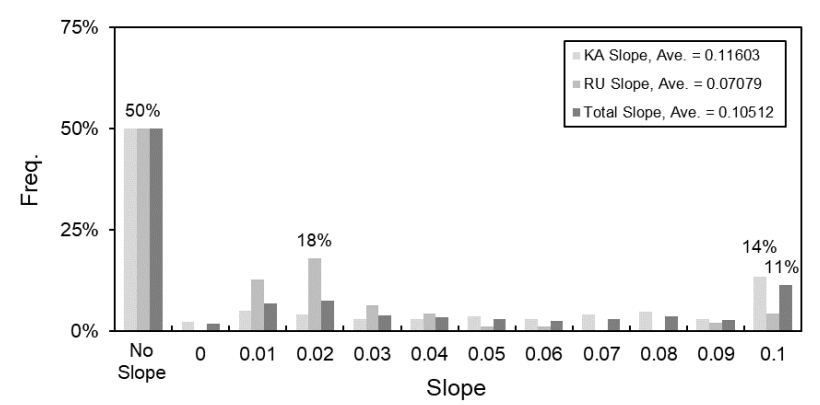

Fig. 8. Beach slope distribution for Karanganom (KA) and Rawaurip (RU)

The beach slope value is divided into beach slope classes with an interval of 0.01 between 0 to 0.1 , as well

\subsection{Beach slope spatial distribution}

The beach slope is calculated from the gradient value of linear regression of the tidal elevation against the horizontal tidal run-up distance measured from a benchmark. The slope is calculated by taking a sample, the distance between transects, every 5 meters along the shoreline so the beach slope spatial distribution will be obtained the same along the surveyed beach.

The spatial distribution of beach slopes in Karanganom and Rawaurip shows a large amount of vegetation indicated by the no slope class on the map (Fig. 7). In Karanganom more slopes are quite steep, although there are also gentle and no slopes, especially in the mangrove vegetation area. Meanwhile, in Rawaurip, the spatial distribution is dominated by gentle slopes and no slopes, besides that there are also quite steep slopes in certain areas.

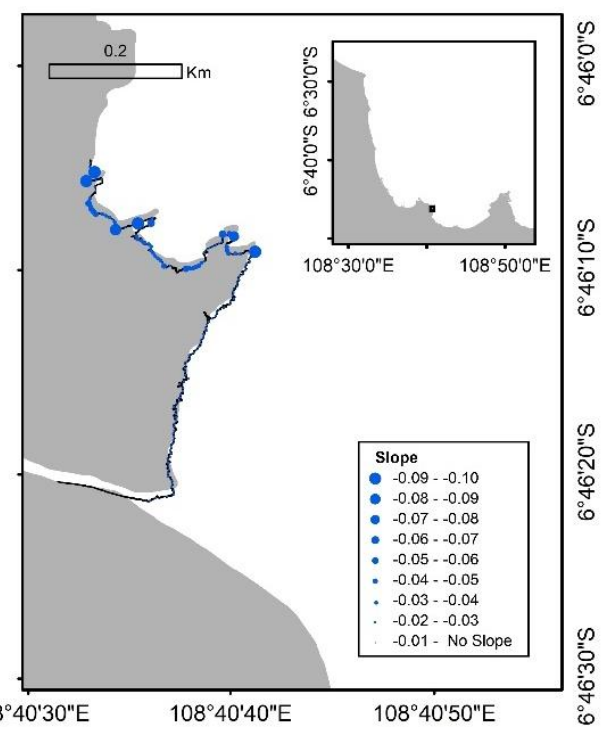

as no slope is also plotted into the histogram. The Karanganom and Rawaurip data are then combined to obtain a representation of the two areas and plotted as Total Slope. From the beach slope histogram, it is found that no slope class is dominated both in Karanganom, Rawaurip, and Total. With the condition of the beach having a slope value, Karanganom is dominated by a steeper slope of 0.1 and Rawaurip is dominated by a gentler slope of 0.02 . The two average values of the beach slope also show the same tendency, with 0.116 and 0.070 , respectively.

\section{Discussion}

Beach slopes, more easily, can also be calculated based on a combination of topographic and bathymetric data $[10,25,54]$. If the combined data is available, the transect on the beach of interest can then be ordered so that the elevation value is obtained with respect to the cross-shore horizontal distance. The ratio of elevation and distance can then be calculated as the beach slope. 
Elevation model data with a wide spatial scale are usually obtained from satellites or assimilation data, which sometimes have low resolution and are less reliable, especially in coastal areas due to loss of shoreline shape details. While elevation in the surf zone (bathymetry) is usually difficult to obtain [13] so global data is still relied on which is also low in resolution.

UAV in this case is an efficient solution, offering lowcost and high-resolution surveys at the same time. Elevation model data (Digital Surface Model) can be generated from drone mapping technology with the application of the structure from motion technique $[30,55]$. However, mapping in coastal areas has several problems, one of which is the possibility of a lot of noise and errors in the resulting data. In the coastal area, the shoreline, as the boundary of the wetting and drying area, is constantly changing. In wet or water areas, sun glint needs to be minimized because the water surface allows reflections and causes misalignments in the photogrammetric workflow. This misalignment occurs because the rendering process of point-cloud density and accuracy is not good enough. In addition, the presence of coastal winds can also cause the water surface to move and cause image distortion [31,56,57]. Although in some specific cases, underwater DSM can also be extracted, which is limited to clear water conditions and shallow depths $[31,38]$. UAVs, which have low survey operational costs, allow for mapping the area multiple times as a solution to overcome dynamic shorelines.

Ideally the maximum and minimum tides are needed in order to fully represent the beach slope. However, these tidal conditions are very specific and may be difficult to find because of the very long period. The timing of these conditions can also occur at night when mapping with UAVs cannot be carried out. Between the two extreme conditions, it is also better to do several measurements so that the linear regression is more fit. Likewise, when relying on the use of a single DSM measurement which must also be at the lowest low tide. This condition is necessary so that the DSM will cover areas that are actively experiencing shoreline changes due to tides (as the definition of beach face). Therefore, timing in extreme conditions to carry out mapping, both maximum and minimum tides, is considered ineffective in obtaining beach slopes.

Tides as elevations that oscillate against a certain sea level and complete one cycle, either twice (semidiurnal), once (diurnal), or mixed (mixed) in one day, are then utilized in this technique. Mapping of coastal areas is carried out several times a day or in a period that is considered to have no significant changes due to erosion or accretion. Linear regression is then used to obtain the gradient of elevation change with respect to the horizontal distance. This can be done because linear regression can represent the beach slope with the condition that the beach profile is in a static beach condition. The more mapping is done, the linear regression will be more fit and the beach slope obtained will be more representative. Meanwhile, quite a lot of mapping can also potentially double the operational costs of the survey. Two-hour mapping, as in this study, can be an optimal option, with fewer observations and significant changes due to tides are still obtained.
As comparison data, data on the grain size of the sediment around the study site is also provided to estimate the beach slope. Other values of the beach slope obtained from other studies are also provided. Sediment grain size distribution is plotted into a cumulative distribution graph (Fig. 9) based on grain size and the sediment diameter value is obtained which represents $50 \%$ cumulative percentile value $(D 50)$.

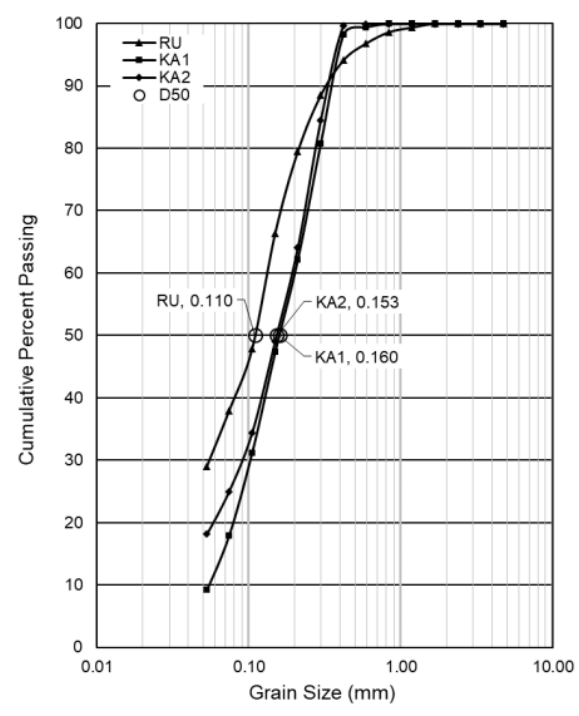

Fig. 9. Cumulative grain size distribution

This value is then used as a variable in the beach slope formula by [23]. In addition to the grain size of the sediment, the wave climate in a year is also needed to determine beach exposure as a determinant of which formula is used. Wave data from European Centre for Medium-Range Weather Forecasts (ECMWF) is then used to obtain wave climate information. The waves for 2020 are then reviewed and estimated how many significant wave heights offshore exceed 12 hours in one year. For CCA waters, almost all of the waves are below $1 \mathrm{~m}$ and make this area a protected beach. The inverse beach slope for this type is calculated according to Equation 2, where $s^{-1}$ is the inverse beach slope and $d$ is sediment grain size in millimeters, represents by $D 50$.

$$
s^{-1}=3.1 d^{-1.1}
$$

In the graph of the cumulative grain size distribution of the sediment, the mean $D 50$ for CCA is 0.141 based on the average value of KA1, KA2, and RU. So, with the McFall equation, the beach slope value will be 0.04 . The beach slope values for each area, their averages, comparisons with other studies, and with the techniques used in this study are shown in Table 2. CCA beach slope based on UAV Mapping is calculated by averaging the value of beach slope based on UAV Mapping in Karanganom and Rawaurip. The techniques in this study show some similarities to other beach slope estimation methods. Note that beach slope estimates based on sediment grain size are not a reference. The assumption of uniform grain size of sediments, the presence of coastal vegetation, and coastal structures, makes this beach slope estimation method less reliable. While using UAV mapping technology, the beach slope obtained can show 
spatial variability, especially in the mangrove vegetation area which is in accordance with the actual situation.

Table 2. Beach slope value comparison

\begin{tabular}{lcccc}
\hline & Ref. & CCA & KA & RU \\
\hline$D 50(\mathrm{~mm})$ & - & 0.141 & 0.156 & 0.110 \\
\hline Slope & & & & \\
\hline UAV Mapping & - & 0.11 & 0.12 & 0.07 \\
McFall (2019) Formula & {$[23]$} & 0.04 & 0.04 & 0.03 \\
Faturrachman et al. (2003) & {$[58]$} & 0.12 & - & - \\
Suhendra et al. (2018) & {$[43]$} & 0.04 & - & 0.07 \\
Kenedi (2017) & {$[46]$} & 0.01 & - & 0.01 \\
\hline
\end{tabular}

By considering the practicality of a method based on the spatial and temporal scale of interest and the use of low operating costs, the use of UAV is considered as a method with high accuracy, speed, and efficiency, hence making it suitable for beach slope spatial mapping. The use of UAV is expected to cover areas with difficult accessibility to solve ground-truthing problems while still maintaining high accuracy and resolution. In maintaining high accuracy, UAV mapping technology needs to be supported by the use of GCPs. However, the use of GCPs and their position measurement is still limited by the accessibility of the area, although only a few measurement points are required. The muddy beach conditions will be very difficult to access, both for GCP placement and position measurement. In coastal areas where there is mangrove vegetation, the same thing happens. Flat areas that are difficult to find due to the presence of mangrove vegetation will make it difficult to locate and measure GCPs. To address this, the GCP is placed in a location that can still be accessed on the condition that it is still within the mapped area. The shape and size of the mapping area can be adjusted so that it can map an affordable GCP. This can risk increasing survey time and costs but is the only way to maintain the accuracy of UAV mapping.

\section{Conclusions}

This paper has demonstrated a new method using UAV mapping technology to calculate the beach slope and map its spatial distribution. Beach slope is simply calculated based on the ratio of vertical elevation to horizontal distance. Based on this, the vertical elevation is determined from the tidal elevation which is free and easy to access from various models and global datasets. Meanwhile, the horizontal distance is calculated from the difference in the distance between several shoreline positions with different tidal conditions. By utilizing this dataset, the beach slope can easily be calculated by comparing the vertical to the horizontal or the gradient from the linear regression.

This method is then demonstrated by applying it to the Cirebon Coastal Area (CCA) as an area with limited accessibility for conducting a ground survey while more sophisticated equipment is also limited. By utilizing drone mapping technology and using the techniques described in this paper, it was found that in total, the CCA was dominated by no slope class of about $50 \%$ (due to the presence of vegetation) and 0.105 of average beach slope with a slope in class 0.1 of $11 \%$. Karanganom is dominated by a steeper beach slope $(0.116$ of average and $14 \%$ for 0.1 class) compared to Rawaurip (0.070 of average and $18 \%$ for 0.02 class). The result of beach slope calculation using this technique shows some suitability with other studies although it is not specific to have the same value (Table 2). Specific similarities of the beach slope value might be difficult to obtain, due to different area coverage and methods (other studies may only use one transect and resolution used may be very low compare to this method).

This technique has demonstrated a successful implementation and being considered as an efficient method of calculating and mapping the spatial distribution of beach slopes. UAV mapping technology provides an alternative method with lower survey operational costs. Meanwhile, when compared to ground surveys, this method is less labor-intensive and fast in mapping large areas. Further development of this technique will focus on its application to other types of beaches such as sandy and gravel. Equipment system upgrades such as the use of attached RTK on UAVs will also be considered. Meanwhile, the timing of the mapping so that the beach slope can be obtained which may be more representative will also be analyzed comprehensively in increasing the effectiveness of this technique.

\section{Acknowledgments}

The authors would like to thank M. Andi Afif Wicaksono and Martin Yahya Surya for their assistance with the survey.

This research was a part of the project titled "Marine Science \& Technology Cooperation between Korea and Indonesia (20180319)" and "Ocean and Coastal Basic Survey and Capacity Enhancement in Cirebon, Indonesia (G52440)" funded by the Ministry of Oceans and Fisheries, Korea.

\section{References}

1. N. C. Kraus, in Encycl. Earth Sci. Ser., edited by M. L. Schwartz (Springer Netherlands, Dordrecht, 2005), pp. 169-172

2. M. Z. Lubis and U. Amri, Proc. 2018 Int. Conf. Appl. Eng. ICAE 20181 (2018)

3. Y. Rosnan and E. H. Ariffin, Int. Annu. Symp. Univ. Malaysia Teren. 553 (2010)

4. M. J. A. Christianen, J. van Belzen, P. M. J. Herman, M. M. van Katwijk, L. P. M. Lamers, P. J. M. van Leent, and T. J. Bouma, PLoS One 8, (2013)

5. M. K. Lowe, F. A. F. Adnan, S. M. Hamylton, R. C. Carvalho, and C. D. Woodroffe, Drones 3, 1 (2019)

6. K. Jun, B. H. Jun, H. Lee, S. Kim, and W. Tak, J. Coast. Res. 85, 811 (2018)

7. G. Guannel, K. Arkema, P. Ruggiero, and G. Verutes, PLoS One 11, 1 (2016)

8. M. J. Chrzastowski, Encycl. Earth Sci. Ser. (2005)

9. USACE, Coastal Engineering Manual (CEM), Engineer Manual 1110-2-1100 (USACE, 
Washington D.C., 2008)

10. P. Athanasiou, A. Van Dongeren, A. Giardino, M. Vousdoukas, S. Gaytan-Aguilar, and R.

Ranasinghe, Earth Syst. Sci. Data 11, 1515 (2019)

11. H. Kim, K. Hall, J.-Y. Jin, G.-S. Park, and J. Lee, J. Meas. Eng. 2, 29 (2014)

12. K. S. Doran, J. W. Long, and J. R. Overbeck, 1 (2015)

13. K. Vos, M. D. Harley, K. D. Splinter, A. Walker, and I. L. Turner, Geophys. Res. Lett. 47, (2020)

14. B. Greenwood, Encycl. Earth Sci. Ser. (2018)

15. S. P. C. Astiti, T. Osawa, and I. W. Nuarsa, ECOTROPHIC J. Ilmu Lingkung. (Journal Environ. Sci. 13, 191 (2019)

16. Q. Liu and J. C. Trinder, Adv. Remote Sens. Technol. Synth. Aperture Radar Appl. Tsunami Disasters, Infrastruct. 1 (2019)

17. A. Wicaksono, P. Wicaksono, N. Khakhim, N. M. Farda, and M. A. Marfai, J. Appl. Geospatial Inf. 2, 145 (2018)

18. V. C. Hoang, H. Tanaka, and Y. Mitobe, Geosci. 7, (2017)

19. K. Vos, M. D. Harley, K. D. Splinter, J. A. Simmons, and I. L. Turner, Coast. Eng. 150, 160 (2019)

20. K. Vos, K. D. Splinter, M. D. Harley, J. A. Simmons, and I. L. Turner, Environ. Model. Softw. 122, 104528 (2019)

21. Y. Liu, H. Huang, Z. Qiu, and J. Fan, Int. J. Appl. Earth Obs. Geoinf. 23, 165 (2013)

22. N. Bujan, R. Cox, and G. Masselink, Mar. Geol. 417, 106012 (2019)

23. B. C. McFall, J. Coast. Res. 35, 1080 (2019)

24. S. Purnawan, N. A. Mailala, S. Karina, Muhammad, I. Setiawan, and Y. Ilhamsyah, IOP Conf. Ser. Earth Environ. Sci. 176, (2018)

25. S. Rodríguez-Polo, L. Del Río, and J. Benavente, J. Coast. Res. 85, 306 (2018)

26. M. Leadon, J. Coast. Res. 31, 1375 (2015)

27. M. D. Harley, I. L. Turner, A. D. Short, and R. Ranasinghe, Coast. Eng. 58, 194 (2011)

28. K. O. Emery, Limnol. Oceanogr. 6, 90 (1961)

29. S. A. Gulyaev and J. S. Buckeridge, J. Coast. Res. 20, 871 (2004)

30. Z. Yin, Analysis of Coastal Erosion between Different Flights of UAV, Lund University, 2021

31. E. Casella, A. Collin, D. Harris, S. Ferse, S. Bejarano, V. Parravicini, J. L. Hench, and A. Rovere, Coral Reefs 36, 269 (2017)

32. W. J. Tak, K. W. Jun, S. D. Kim, and H. J. Lee, J. Coast. Res. 95, 674 (2020)

33. M. K. Bennett, N. Younes, and K. Joyce, Drones 4, $1(2020)$

34. N. Wahidin and R. M. Abdullah, Pros. Semin. Nas. Inov. Iptek Perikan. Dan Kelaut. I I, 621 (2018)

35. C. I. Yoo and T. S. Oh, Int. Arch. Photogramm. Remote Sens. Spat. Inf. Sci. - ISPRS Arch. 41, 1201 (2016)

36. R. H. Narashid, M. A. Zakaria, F. A. Mohd, M. F. Pa'Suya, N. Talib, and E. H. Ariffin, IOP Conf. Ser. Earth Environ. Sci. 620, (2021)

37. A. Chennu, P. Färber, G. De'ath, D. De Beer, and K. E. Fabricius, Sci. Rep. 7, 1 (2017)
38. P. Agrafiotis, D. Skarlatos, A. Georgopoulos, and K. Karantzalos, ISPRS Ann. Photogramm. Remote Sens. Spat. Inf. Sci. 42, 9 (2019)

39. N. Long, B. Millescamps, B. Guillot, F. Pouget, and X. Bertin, Remote Sens. 8, 1 (2016)

40. M. Erena, J. F. Atenza, S. García-Galiano, J. A. Domínguez, and J. M. Bernabé, Water (Switzerland) 11, (2019)

41. W. W. Chen and H. K. Chang, Estuar. Coast. Shelf Sci. 84, 54 (2009)

42. C. B. of S. BPS, Kabupaten Indramayu Dalam Angka 2018 (Kabupaten Indramayu, 2020)

43. Suhendra, A. Amron, and E. Hilmi, E3S Web Conf. 47, (2018)

44. S. A. Harahap, N. P. Purba, and M. L. Syamsuddin, World Sci. News 138, 79 (2019)

45. A. Heriati and S. Husrin, Reka Geomatika 2017, 52 (2018)

46. B. M. Kenedi, Analisis Perubahan Garis Pantai Dengan Menggunakan Citra Satelit Landsat Di Pesisir Kabupaten Tangerang, Banten, Institut Pertanian Bogor, 2017

47. E. H. Boak and I. L. Turner, J. Coast. Res. 21, 688 (2005)

48. V. J. Markose, B. Rajan, R. S. Kankara, S. Chenthamil Selvan, and S. Dhanalakshmi, Environ. Earth Sci. 75, (2016)

49. R. S. Kankara, S. C. Selvan, V. J. Markose, B. Rajan, and S. Arockiaraj, Procedia Eng. 116, 855 (2015)

50. S. Toure, O. Diop, K. Kpalma, and A. S. Maiga, ISPRS Int. J. Geo-Information 8, (2019)

51. and S. L. H. S. Erofeeva, L. Padman, GitHub (2020)

52. G. D. Egbert and S. Y. Erofeeva, J. Atmos. Ocean. Technol. 19, 183 (2002)

53. A. Thieler, E. R., Himmelstoss, E. A., Zichichi, J. L., \& Ergul, Digital Shoreline Analysis System (DSAS) Version 4.0 - An ArcGIS Extension for Calculating Shoreline Change (U.S. Geological Survey Open-File Report 2008 (p. 1278)., 2009)

54. Y. Saito, Encycl. Earth Sci. Ser. (2005)

55. F. H. Yeh, C. J. Huang, J. Y. Han, and L. Ge, MATEC Web Conf. 147, 1 (2018)

56. E. Casella, A. Rovere, A. Pedroncini, L. Mucerino, M. Casella, L. A. Cusati, M. Vacchi, M. Ferrari, and M. Firpo, Estuar. Coast. Shelf Sci. 149, 160 (2014)

57. P. Zinke and C. Flener, Vann 48, 351 (2013)

58. F. A. and R. Purnomo, J. Geol. Kelaut. 1, 15 (2003) 